\title{
The D-side of COVID-19: musculoskeletal benefits of vitamin D and beyond
}

\author{
Flavia Tramontana ${ }^{1} \cdot$ Nicola Napoli $\mathbb{C}^{1,2} \cdot$ Ghada El-Hajj Fuleihan ${ }^{3,4} \cdot$ Rocky Strollo $^{1}$
}

Received: 7 June 2020 / Accepted: 26 June 2020 / Published online: 6 July 2020

(c) Springer Science+Business Media, LLC, part of Springer Nature 2020

\begin{abstract}
Coronavirus 2019 disease (COVID-19) mostly adversely affects the elderly, a population at higher risk for low serum 25-hydroxyvitamin D (25(OH)D) levels. In this viewpoint, we highlight the well-known musculoskeletal properties of vitamin D, which are particularly relevant in the context of COVID-19, suggesting further potential benefits through extraskeletal effects. Maintaining optimal $25(\mathrm{OH}) \mathrm{D}$ is crucial to prevent falls, frailty and fractures in elderly patients, with low activity levels due to lockdown, or who are relatively immobilized during hospitalization and after discharge for prolonged periods of time. Hypovitaminosis D is also associated with susceptibility to respiratory infections, admissions to the intensive care unit, and mortality. We underscore the importance of achieving desirable serum 25(OH)D in COVID-19 elderly patients, to ensure beneficial musculoskeletal effects and possibly respiratory effects of vitamin $\mathrm{D}$, in the context of COVID-19.
\end{abstract}

Keywords COVID-19 $\cdot$ Vitamin D $\cdot$ Elderly $\cdot$ Frailty $\cdot$ ARDS $\cdot$ Fractures

Severe Acute Respiratory Syndrome Coronavirus-2 (SARS$\mathrm{CoV}-2)$ pandemic has repositioned healthcare front and center and rendered prevention and treatment strategies a foremost global priority. COVID-19-associated mortality and morbidity increase with age (https://www.cdc.gov/ coronavirus/2019-nCoV/index.html). Overall, $45 \%$ of hospitalizations, $53 \%$ of intensive care unit (ICU) admissions,

Supplementary Information The online version of this article (https://doi.org/10.1007/s12020-020-02407-0) contains supplementary material, which is available to authorised users.

Nicola Napoli

n.napoli@unicampus.it

$\triangle$ Ghada El-Hajj Fuleihan

gf01@aub.edu.lb

1 Unit of Endocrinology and Diabetes, Department of Medicine, Campus Bio-Medico University of Rome, Via Alvaro di Portillo 21, 00128 Rome, Italy

2 Division of Bone and Mineral Diseases, Washington University in St Louis, St Louis, MO, USA

3 Calcium Metabolism and Osteoporosis Program, American University of Beirut, Beirut, Lebanon

4 Scholars in HeAlth Research Program (SHARP), American University of Beirut Medical Center, Beirut, Lebanon and $80 \%$ of deaths associated with COVID-19 were among the elderly (https://www.cdc.gov/coronavirus/2019-nCoV/ index.html). Serum 25(OH)D level is the best index of vitamin D nutritional status [1]. Hypovitaminosis D is highly prevalent in the elderly because of the impaired ability to synthetized vitamin $\mathrm{D}$ by the skin, limited sun exposure and malabsorption $[2,3]$.

The putative beneficial effect for vitamin D in COVID19 patients is based on in vitro and in vivo evidence regarding its role as musculoskeletal and immune modulator, and its efficacy in co-morbidities these patients commonly suffer from, notoriously pulmonary complications. Patients affected with COVID-19 undergo prolonged hospitalization, are more likely to require ICU admission, and relative or complete immobilization. Full recovery and resumption in activities of daily living may take weeks following discharge. The elderly normally experiences a progressive age-related decline in muscle function. Immobilization exacerbates this process through a fast reduction in protein synthesis by $30 \%$, lower extremity lean mass by $6.3 \%$ and muscle strength by $15.6 \%$ [4]. The end result of muscle loss is an impairment in daily living activities after discharge and a potentially increasing risk of falls, fractures and death [4]. Acute and chronic immobilization also promotes bone resorption [5] and it is likely that elderly, the large proportion of COVID-19 patients, will experience 
even more severe bone loss due to hypersecretion of inflammatory cytokines [6] and treatment with high doses of glucocorticoids. The detrimental effect on bone mass that ensues may result in bone loss, frailty and a higher risk of fractures [7]. Vitamin D replacement, combined with calcium, has been shown to be effective in reducing fracture risk. The most consistent protective effect is in reducing the risk of hip fracture by $16-33 \%$, and of any fracture by $5-19 \%$, compared to placebo or control [8]. This effect is demonstrated when combining trials in communitydwelling and institutionalized individuals but it is likely driven by data from institutionalized individuals, as consistently shown in three meta-analyses [8]. Importantly, hip fractures incur mortality rates as high as $15-30 \%$ within 1-3 years, and half of subjects lose functional independence [9]. Vitamin D also has a direct effect on muscle health by improving muscle strength and function [10, 11]. These muscular benefits of vitamin D should be also translated into a reduction of risk of falls. Although results from meta-analyses on the effect of vitamin D on falls are variable, they are explained by differences in interventions, populations of interest and trial duration. Importantly, the 2018 Cochrane meta-analysis on interventions for fall prevention demonstrated a $28 \%$ risk reduction in the rate of falls with vitamin $\mathrm{D}$ supplementation in patients in care facilities [12]. The projected beneficial effects of vitamin D on muscle and bone in COVID-19 patients would ultimately translate into a reduction of risk of falls and fractures, throughout hospitalization and rehabilitation.

Specific extra-skeletal properties of vitamin $\mathrm{D}$ cannot be ignored [13]. COVID-19 infection is characterized by an increase in pro-inflammatory cytokines, that in severe cases triggers the dreaded "cytokines storm" leading to lung as well as systemic inflammation. Elevated serum levels of interleukin-6 and other pro-inflammatory cytokines are hallmarks of systemic inflammation of COVID-19, which is associated with disease severity and adverse clinical outcomes [14]. Therefore, modulation of inflammatory response has been suggested as a potential therapeutic strategy [15]. Vitamin D may modulate inflammatory response through its effects on innate and adaptive immunity [16]. Calcitriol, the active vitamin $\mathrm{D}$ metabolite, targets macrophages, activated $\mathrm{B}$ and $\mathrm{T}$ cells, through vitamin $\mathrm{D}$ receptors, and induces immunoglobulin and cytokine production $[16,17]$. It is also involved in the toll-like receptor (TLR) 2/1 pathway [16]. Although the pathophysiology of the virulence of Coronaviruses is unfolding, TLR2 is known to recognize also viral proteins, and therefore may be potentially involved in the cellular pathway leading to COVID-19 pulmonary complications.

Low serum concentration of $25(\mathrm{OH}) \mathrm{D}$ is associated with impaired respiratory health and increased susceptibility to acute respiratory infections [18]. Sixty-seven to $85 \%$ percent of patients with COVID-19 experience acute respiratory distress syndrome (ARDS) which represents one of the leading causes of mortality (https://www.cdc.gov/corona virus/2019-nCoV/index.html). Previous studies have found that vitamin $\mathrm{D}$ deficiency was ubiquitous in patients with ARDS while serum $1,25(\mathrm{OH})_{2} \mathrm{D}$ was higher in those who survived compared to non-survivors [19]. A meta-analysis of 25 randomized controlled clinical trials showed that vitamin D supplementation prevents acute respiratory infections by $12 \%$ (adjusted OR:0.88, 95\% CI 0.81-0.96), mostly in those with low $25(\mathrm{OH}) \mathrm{D}$ levels at baseline (adjusted OR:0.58, 95\% CI -0.40 to 0.82 ) [18]. In chronic obstructive pulmonary disease, a risk factor for COVID-19 complications, muscle weakness is associated with poor prognosis independently of lung function [20], and could improve with vitamin D. Vitamin D deficiency is common in critically ill patients and associated with disease severity, higher mortality and reduced survival time in ICU [21]. Likewise, in patients with pneumonia vitamin $\mathrm{D}$ deficiency resulted in a higher risk to ICU admission and mortality [22]. In a retrospective observational study on 655 ICU patients, an increased chance of survival was reported in those with $25(\mathrm{OH}) \mathrm{D}>20 \mathrm{ng} / \mathrm{mL}$ compared to those with vitamin $\mathrm{D}$ deficiency [23]. In a randomized double-blind, placebo-controlled trial in critically ill patients with vitamin $\mathrm{D}$ deficiency, high-dose vitamin $\mathrm{D}$ did not reduce hospital length of stay, hospital mortality, or 6-month mortality. However, investigators observed a lower hospital mortality in the severe vitamin D deficiency subgroup $(25(\mathrm{OH}) \mathrm{D} \leq$ $12 \mathrm{ng} / \mathrm{mL}$ ) [24].

Taken together all these data may suggest a broader potential of vitamin D [25]; while effects on muscle-skeletal outcomes have been largely proved, potential benefits on the immune system require more evidence.

In conclusion, reaching an optimal vitamin D status will be beneficial for COVID-19 patients in order to prevent falls, frailty, and fractures either during and after hospitalization. Preventive measures should include also supervised physical activity, adequate intake of calcium, and other micronutrients, which are known to improve bone mass and sarcopenia also in the elderly and frail subjects [26-29].

We recommend daily or weekly regimens with $800 \mathrm{IU} /$ day of cholecalciferol (or equivalents) [30, 31]; higher doses, if needed (for e.g. if vitamin D deficiency), should be given according to the local guidelines, and provided they do not exceed the upper tolerable level of 4000 IU/day [32]. Lessons learned from large trials teach us that more is not better, and that bolus doses can be harmful, increasing bone resorption and fall risk [33]. On-going vitamin D trials will inform best practices on optimal dosing for patients with COVID-19 and will provide the needed evidence for 
proving its putative beneficial effect on immune-modulation and respiratory function.

Facing the COVID-19 pandemic, many clinical services including osteoporosis outpatient clinics, rehabilitation facilities have been closed. It is crucial to intensify efforts to improve the current management of muscle and bone health in COVID-19 patients, and strive to restore functional ability and quality of life [34].

Acknowledgements The authors thank Drs Aya Bassatne, Maya Basbous, Ola El-Zein, and Mrs Maya Rahme for their contributions to the literature search and screening of relevant papers retrieved.

\section{Compliance with ethical standards}

Conflict of interest The authors declare that they have no conflict of interest.

Publisher's note Springer Nature remains neutral with regard to jurisdictional claims in published maps and institutional affiliations.

\section{References}

1. C.T. Sempos, A.C. Heijboer, D.D. Bikle, J. Bollerslev, R. Bouillon, P.M. Brannon, H.F. Deluca, G. Jones, C.F. Munns, J.P. Bilezikian, Vitamin D assays and the definition of hypovitaminosis D: results from the First International Conference on Controversies in Vitamin D. Br. J. Clin. Pharmacol. 25, 2194-2207 (2018)

2. M.F. Holick, Vitamin D deficiency. N. Engl. J. Med. 357, 266-281 (2007)

3. P. Ebeling, R. Adler, G. Jones, U. Liberman, G. Mazziotti, S. Minisola, C. Munns, N. Napoli, A. Pittas, A. Giustina, J. Bilezikian, R. Rizzoli, Therapeutics of vitamin D. Eur. J. Endocrinol. 179, R239-R259 (2018)

4. P. Kortebein, A. Ferrando, J. Lombeida, W. Wolfe, Effect of 10 days of bed rest on skeletal muscle in healthy older adults. JAMA 297, 1772-1774 (2007)

5. J.S. Chen, I.D. Cameron, R.G. Cumming, S.R. Lord, L.M. March, P.N. Sambrook, J.M. Simpson, M.J. Seibel, Effect of age-related chronic immobility on markers of bone turnover. J. Bone Miner. Res. 21, 324-331 (2006)

6. T. Nakashima, H. Takayanagi, Osteoimmunology: crosstalk between the immune and bone systems. J. Clin. Immunol. 29, 555-567 (2009)

7. N. Napoli, R. Strollo, D. Sprini, E. Maddaloni, G.B. Rini, E. Carmina, Serum 25-OH vitamin D in relation to bone mineral density and bone turnover. Int. J. Endocrinol. 2014, 1-5 (2014)

8. M. Chakhtoura, N. Chamoun, M. Rahme, G. El-Hajj Fuleihan, Impact of vitamin D supplementation on falls and fractures-a critical appraisal of the quality of the evidence and an overview of the available guidelines. Bone 131, 115112 (2020)

9. G.S. Tajeu, E. Delzell, W. Smith, T. Arora, J.R. Curtis, K.G. Saag, M.A. Morrisey, H. Yun, M.L. Kilgore, Death, debility, and destitution following hip fracture. J. Gerontol. Ser. A Biol. Sci. Med. Sci. 69 A, 346-353 (2014)

10. H.C.J.P. Janssen, M.M. Samson, H.J.J. Verhaar, Vitamin D deficiency, muscle function, and falls in elderly people. Am. J. Clin. Nutr. 75, 611-615 (2002)

11. N. Napoli, S. Vattikuti, C. Ma, A. Rastelli, A. Rayani, R. Donepudi, High prevalence of low vitamin D and musculoskeletal complaints in women with breast cancer. Breast J. 16, 609-616 (2010)

12. I.D. Cameron, S.M. Dyer, C.E. Panagoda, G.R. Murray, K.D. Hill, R.G. Cumming, N. Kerse, Interventions for preventing falls in older people in care facilities and hospitals. Cochrane Database Syst. Rev. 2018, 1-332 (2018)

13. A. Giustina, R.A. Adler, N. Binkley, R. Bouillon, P.R. Ebeling, M. Lazaretti-castro, C. Marcocci, R. Rizzoli, C.T. Sempos, Controversies in vitamin D: summary statement from an international conference. J. Clin. Endocrinol. Metab. 104, 234-240 (2019)

14. Q. Ruan, K. Yang, W. Wang, L. Jiang, J. Song, Clinical predictors of mortality due to COVID-19 based on an analysis of data of 150 patients from Wuhan, China. Intensive Care Med. 3, 1-3 (2020)

15. P. Mehta, D.F. McAuley, M. Brown, E. Sanchez, R.S. Tattersall, J.J. Manson, COVID-19: consider cytokine storm syndromes and immunosuppression. Lancet 395, 1033-1034 (2020)

16. J.R. Mora, M. Iwata, U.H. Von Andrian, Vitamin effects on the immune system: vitamins A and D take centre stage. Nat. Rev. Immunol. 8, 685-698 (2008)

17. C.L. Greiller, A.R. Martineau, Modulation of the immune response to respiratory viruses by vitamin D. Nutrients $\mathbf{7}$, 4240-4270 (2015)

18. A.R. Martineau, D.A. Jolliffe, R.L. Hooper, L. Greenberg, J.F. Aloia, P. Bergman, G. Dubnov-Raz, S. Esposito, D. Ganmaa, A. A. Ginde, E.C. Goodall, C.C. Grant, C.J. Griffiths, W. Janssens, I. Laaksi, S. Manaseki-Holland, D. Mauger, D.R. Murdoch, R. Neale, J.R. Rees, S. Simpson, I. Stelmach, G.T. Kumar, M. Urashima, C.A. Camargo, Vitamin D supplementation to prevent acute respiratory tract infections: systematic review and metaanalysis of individual participant data. BMJ 356, 1-14 (2017)

19. R.C.A. Dancer, D. Parekh, S. Lax, V. D'Souza, S. Zheng, C.R. Bassford, D. Park, D.G. Bartis, R. Mahida, A.M. Turner, E. Sapey, W. Wei, B. Naidu, P.M. Stewart, W.D. Fraser, K.B. Christopher, M.S. Cooper, F. Gao, D.M. Sansom, A.R. Martineau, G.D. Perkins, D.R. Thickett, Vitamin D deficiency contributes directly to the acute respiratory distress syndrome (ARDS). Thorax 70, 617-624 (2015)

20. S.E. Jones, M. Maddocks, S.S.C. Kon, J.L. Canavan, C.M. Nolan, A.L. Clark, M.I. Polkey, W.D.C. Man, Sarcopenia in CODP: prevalence, clinical correlates and response to pulmonary rehabilitation. Thorax 70, 213-218 (2015)

21. R.M. Perron, P. Lee, Efficacy of high-dose vitamin D supplementation in the critically ill patients. Inflamm. Allergy Drug Targets 12, 273-281 (2013)

22. H.H.F. Remmelts, E.M.W. Van De Garde, S.C.A. Meijvis, E.L.G.C. A. Peelen, J.G.M.C. Damoiseaux, J.C. Grutters, D.H. Biesma, W.J. W. Bos, G.T. Rijkers, Addition of Vitamin D status to prognostic scores improves the prediction of outcome in community-acquired pneumonia. Clin. Infect. Dis. 55, 1488-1494 (2012)

23. K. Amrein, P. Zajic, C. Schnedl, A. Waltensdorfer, S. Fruhwald, A. Holl, T.U. Purkart, G. Wünsch, T. Valentin, A. Grisold, T. Stojakovic, S. Amrein, T.R. Pieber, H. Dobnig, Vitamin D status and its association with season, hospital and sepsis mortality in critical illness. Crit. Care 18, 1-12 (2014)

24. T.U. Purkart, A. Waltensdorfer, A. Münch, H. Warnkross, T. Stojakovic, E. Bisping, Effect of high-dose vitamin D3 on hospital length of stay in critically ill patients with vitamin D deficiency the VITdAL-ICU randomized clinical trial. JAMA 15, 1520-1530 (2014)

25. A. Giustina, R.A. Adler, N. Binkley, J. Bollerslev, R. Bouillon, B. Dawson-Hughes, P.R. Ebeling, D. Feldman, A.M. Formenti, M. Lazaretti-Castro, C. Marcocci, R. Rizzoli, C.T. Sempos, J.P. Bilezikian, Consensus statement from 2nd International Conference on Controversies in Vitamin D. Rev. Endocr. Metab. Disord. 21, 89-116 (2020) 
26. G. Iolascon, R. Gimigliano, M. Bianco, A. de Sire, A. Moretti, A. Giusti, N. Malavolta, S. Migliaccio, A. Migliore, N. Napoli, P. Piscitelli, G. Resmini, U. Tarantino, F. Gimigliano, Are dietary supplements and nutraceuticals effective for musculoskeletal health and cognitive function? A scoping review. J. Nutr. Heal. Aging 21, 527-538 (2017)

27. R. Armamento-Villareal, L. Aguirre, N. Napoli, K. Shah, T. Hilton, D.R. Sinacore, C. Qualls, D.T. Villareal, Changes in thigh muscle volume predict bone mineral density response to lifestyle therapy in frail, obese older adults. Osteoporos. Int. 25, 551-558 (2014)

28. N. Napoli, J. Thompson, R. Civitelli, R.C. Armamento-Villareal, Effects of dietary calcium compared with calcium supplements on estrogen metabolism and bone mineral density. Am. J. Clin. Nutr. 85, 1428-1433 (2007)

29. L. Di Filippo, A.M. Formenti, M. Rovere-querini, M. Carlucci, C. Conte, F. Ciceri, A. Zangrillo, A. Giustina. Hypocalcemia is highly prevalent and predicts hospitalization in patients with COVID-19. Endocrine, 1-4 (2020)

30. R.B. Conley, G. Adib, R.A. Adler, K.E. Åkesson, I.M. Alexander, K.C. Amenta, R.D. Blank, W.T. Brox, E.E. Carmody, K. Chapman-novakofski, B.L. Clarke, K.M. Cody, C. Cooper, C.J. Crandall, D.R. Dirschl, T.J. Eagen, A.L. Elderkin, M. Fujita,
S.L. Greenspan, P. Halbout, M.C. Hochberg, M. Javaid, K.J. Jeray, A.E. Kearns, T. King, T.F. Koinis, J.S. Koontz, M. Ku, C. Lindsey, M. Lorentzon, G.P. Lyritis, L.B. Michaud, A. Miciano, S.N. Morin, N. Mujahid, N. Napoli, T.P. Olenginski, J.E. Puzas, S. Rizou, C.J. Rosen, K. Saag, E. Thompson, L.L. Tosi, H. Tracer, S. Khosla, D.P. Kiel, Secondary fracture prevention: consensus clinical recommendations from a multistakeholder coalition. J. Bone Miner. Res. 35, 36-52 (2020)

31. M. Puig-domingo, A. Marazuela, A. Giustina, COVID-19 and endocrine diseases. A statement from the European Society of Endocrinology. Endocrine 68, 2-5 (2020)

32. Institute of Medicine (US) Committee to Review Dietary Reference Intakes for Vitamin D and Calcium, A.C. Ross, C.L. Taylor, A.L. Yaktine, H.B. Del Valle. Dietary reference intakes for calcium and vitamin D. Washington, DC: The National Academies Press. 1-1115 (2011). https://doi.org/10.17226/13050

33. M. Rossini, S. Adami, O. Viapiana, E. Fracassi, L. Idolazzi, M.R. Povino, D. Gatti, Dose-dependent short-term effects of single high doses of oral vitamin D3 on bone turnover markers. Calcif. Tissue Int. 91, 365-369 (2012)

34. N. Napoli, A.L. Elderkin, D.P. Kiel, D. P., Khosla. Managing fragility fractures during the COVID-19 pandemic. Nat. Endocrinol. (2020). In press https://doi.org/10.1038/s41574-020-0379-z 